\title{
Therapeutic immunisation of rabbits with cottontail rabbit papillomavirus (CRPV) virus-like particles (VLP) induces regression of established papillomas
}

\author{
Vandana A Govan*1, Edward P Rybicki ${ }^{1,2}$ and Anna-Lise Williamson ${ }^{1,3}$
}

Address: ${ }^{1}$ Institute of Infectious Disease and Molecular Medicine, Faculty of Health Sciences, University of Cape Town, Observatory, Cape Town, South Africa, ${ }^{2}$ Department of Molecular \& Cell Biology, University of Cape Town, Observatory, Cape Town, South Africa and ${ }^{3}$ National Health Laboratory Service, Groote Schuur Hospital, Observatory, Cape Town, South Africa

Email: Vandana A Govan* - Vandana.Govan@uct.ac.za; Edward P Rybicki - Ed.Rybicki@uct.ac.za; Anna-Lise Williamson - AnnaLise.Williamson@uct.ac.za

* Corresponding author

Published: 20 March 2008

Virology Journal 2008, 5:45 doi:10.1 186/1743-422X-5-45

This article is available from: http://www.virologyj.com/content/5/l/45

(c) 2008 Govan et al; licensee BioMed Central Ltd.

This is an Open Access article distributed under the terms of the Creative Commons Attribution License (http://creativecommons.org/licenses/by/2.0), which permits unrestricted use, distribution, and reproduction in any medium, provided the original work is properly cited.

\begin{abstract}
There is overwhelming evidence that persistent infection with high-risk human papillomaviruses (HR-HPV) is the main risk factor for invasive cancer of the cervix. Due to this global public health burden, two prophylactic HPV LI virus-like particles (VLP) vaccines have been developed. While these vaccines have demonstrated excellent type-specific prevention of infection by the homologous vaccine types (high and low risk HPV types), no data have been reported on the therapeutic effects in people already infected with the low-risk HPV type. In this study we explored whether regression of CRPV-induced papillomas could be achieved following immunisation of outbred New Zealand White rabbits with CRPV VLPs. Rabbits immunised with CRPV VLPs had papillomas that were significantly smaller compared to the negative control rabbit group $(P \leq 0.05)$. This data demonstrates the therapeutic potential of PV VLPs in a well-understood animal model with potential important implications for human therapeutic vaccination for low-risk HPVs.
\end{abstract}

\section{Findings}

Papillomaviruses (PVs) are small, non-enveloped viruses containing a $8 \mathrm{~kb}$ double-stranded closed circular DNA genome, encoding six early proteins (E1, E2, E4, E5, E6 and E7), two late proteins (L1 and L2) and a non-coding regulatory region, the long-control region (LCR) [1]. The LCR contains the origin of replication; early genes contribute to transformation and viral replication, and the late genes provide capsid proteins [1]. There are over 100 different human PV (HPV) genotypes that have been fully sequenced: the more important of these cause cervical, vulva and vaginal cancers, genital warts and recurrent respiratory papillomatosis. HPVs can be divided into low- risk, non-oncogenic or high-risk oncogenic types [2] according to their ability to cause malignant disease [3]. The most prevalent low-risk types are HPV 6 and 11, which cause $90 \%$ of genital warts (condyloma acuminata), while HPV 16 and 18 are the predominant high-risk types, causing $70 \%$ of cervical cancer and cervical intraepithelial neoplasia (CIN) [2]. Cervical cancer is the second most common cancer among women worldwide and the most common in developing countries [4] contributing significantly to a global public health burden.

In order to reduce the burden of HPV-induced infections, many studies have investigated the efficacy of different 
prophylactic and therapeutic vaccines in various animal models $[5,6]$. Preclinical studies using the cottontail rabbit papillomavirus (CRPV) in rabbits, canine oral papillomavirus (COPV) in dogs and bovine papillomavirus (BPV) in cattle have afforded a better understanding of the molecular mechanism that regulate normal cell growth, steps involved in cancerous cell changes [7] and have examined the efficacy of several delivery systems [5,8-10].

These animal studies have demonstrated that the expression of PV L1 genes in a number of cell systems results in the assembly of virus-like particles (VLPs), which elicit high titers of virus-neutralizing serum antibodies when administered as an immunogen $[11,12]$. As a result of the successful animal preclinical trials, L1 VLPs were effectively used as prophylactic vaccines in human clinical trials. It was demonstrated that the HPV VLP (HPV 6, 11, 16 or 18 ) vaccine was $100 \%$ efficacious in preventing typespecific precancerous lesions of the cervix, vulva, and vagina and effective against genital warts [13-15]. Owing to the promising human clinical trials, this prophylactic quadrivalent HPV (types 6, 11, 16 and 18) L1 recombinant VLP vaccine (Gardasil) produced by Merck was approved and registered by the Food and Drug Administration (FDA) on the 8 June 2006. Furthermore, the second preventative bivalent vaccine, Cervarix (produced by GlaxoSmithKline), which contains HPV types 16/18 L1 VLPs has been approved for use in Australia and is under review in other countries by various regulatory bodies.

However, while the current prophylactic vaccines would be effective in preventing type-specific infection it is not known whether these vaccines would afford protection to women who are already infected with the non-oncogenic HPV-associated disease. Recently, it was demonstrated that women with existing oncogenic HPV DNA infection did not benefit from HPV-16/18 L1 VLP vaccination [16]. Nevertheless, these prophylactic HPV VLP vaccines are formulated with adjuvants and are able to elicit a strong and robust immune response compared to the VLPs alone [17]. Furthermore, the immune responses elicited by the vaccine with adjuvant induced a T helper type 2 (TH2)like response with lasting immunity compared to the VLP vaccine alone [17]. Therefore, this study used the CRPV rabbit model system, to determine whether regression of established CRPV-induced papillomas could be achieved following the vaccination of rabbits with CRPV L1 VLP vaccine, as a pilot investigation for further studies into the use of low risk HPV VLP-based vaccines as a possible therapeutic vaccine strategy.

A successful therapeutic vaccine should elicit a strong cellmediated immune response and induce lesion regression in HPV established infection with no recurrence [18]. Indeed, studies have shown that HPV VLPs are able to induce T-cell proliferative responses in different experimental systems $[19,20]$.

The CRPV L1 VLPs were produced in Spodoptera frugiperda (Sf21) cells via recombinant baculovirus as previously described [10]. Essentially, the CRPV L1 gene was directionally cloned into the pFastBac1 vector (Invitrogen), transfected into DH10Bac-competent Escherichia coli cells to generate bacmids which were then transfected into Sf 21 cells (Invitrogen) according to the manufacturer's Bac-toBac protocol. The infected Sf21 cells were pelleted, resuspended in PBS containing $0.4 \mathrm{~g} / \mathrm{ml} \mathrm{CsCl}$ and complete protease inhibitor (Roche), and sonicated. The sonicated suspension was centrifuged at $100,000 \mathrm{~g}$ at $10^{\circ} \mathrm{C}$ for $24 \mathrm{~h}$. Two distinct bands were observed on the $\mathrm{CsCl}$ gradient: the top band was extracted by puncturing the tubes and dialyzed against PBS (1.47 mM KH2PO4, 10 mMNa2HPO4, $2.7 \mathrm{mMKCl}, 500 \mathrm{mMNaCl}, \mathrm{pH}$ 7.4) for 48 h. Dialyzed protein was divided into 100-l aliquots and frozen at $70^{\circ} \mathrm{C}$ for further use.

As a negative control, the rotavirus VP 6 gene, Edim (kindly provided by Dr M. Dennehy, Genbank accession number DQ019612), cloned in BCG, was used and prepared as previously described and designated pControl [9].

All animal procedures were approved by the Research Ethics Committee, Faculty of Health Sciences, University of Cape Town, South Africa. A total of nine out-bred New Zealand White rabbits (obtained from J.C rabbit Suppliers, South Africa) were infected with infectious CRPV $\left(\mathrm{CRPV}_{\text {Hershey }}\right.$ strain) at $10^{-2}$ and $10^{-3}$ (2 sites per dilution for each rabbit) as previously described [9]. The rabbits were randomly divided into 2 groups, and the papilloma sizes were measured 7 weeks post CRPV infection. All rabbits were immunised subcutaneously at week 8. Group 1 $(\mathrm{n}=5)$ was immunized with CRPV L1 VLPs and group 2 $(\mathrm{n}=4)$ was immunised with pControl $10^{7} \mathrm{cfu} / \mathrm{ml}$, as a negative control. Each rabbit received 3 immunisations at 2 weekly intervals. Starting at week 7 post CRPV infection the papilloma sizes were measured as length $\times$ width $\times$ height in millimetres and the geometric mean diameter (GMD) was calculated for each papilloma every week. The mean GMDs and the standard error of mean (SEM) for each group was plotted against time for sites infected with 10-2 dilution of infectious CRPV. Data were compared using the unpaired non-parametric, Mann-Whitney $U$ test. Differences were considered significant at $P \leq 0.05$.

The rabbits in each group were monitored weekly and papilloma formation was measured each week post CRPV infection. The geometric mean diameter (GMD) for the $10^{-2}$ dilution of virus (two sites per rabbit) was plotted against time after immunisation with CRPV VLPs and 
pControl (Fig. 1). The regression rate of the papillomas at every site for each experimental rabbit group was tabulated in Table 1 . The rabbits immunised with pControl demonstrated no papilloma regression even after the third immunisation and the papillomas grew progressively. Similar progressive papilloma growths were observed in rabbits injected with PBS ( $\mathrm{pH} 7.0$ ) (data not shown). In contrast, the rabbits immunised with CRPV VLPs had papillomas that grew slower after each immunisation and were significantly smaller compared to the control group $(P \leq 0.05)$ (Fig. 1). In addition, rabbits immunised with CRPV VLPs had papillomas that regressed to a GMD $<5$ mm (15 of 20 sites; 75\%) (Table 1) compared to no papilloma reduction in the control group.

The results produced in this study show that immunisation with CRPV L1 VLPs is able to elicit a significant therapeutic effect in rabbits with existing CRPV induced papillomas. This is a novel result, which at first sight has significant implications for therapeutic human vaccina- tion, given the close correspondence of the animal model to human wart pathology. However, the literature is replete with studies that show that HPV L1 VLPs generate mainly humoral responses against type-specific HPVs, and they are only effective in prophylaxis without affording a therapeutic effect against oncogenic HPV-induced infections [16,21].

The rationale for this is that the HPV life-cycle is totally intraepithelial and the virus requires a differentiated squamous epithelium to complete its life cycle and produce infectious viral particles [22]. Furthermore, in late gene expression the viral DNA is often integrated and the L1 gene would probably be disrupted. Thus the levels of L1 expression in cytotoxic T cell-accessible cells would be presumed to be undetectable, possibly preventing a L1specific CTL response [23]. However, in a study by Zhang et al., [24] it was shown that patients with established genital warts were able to induce frequent regression when vaccinated with HPV $6 \mathrm{~b}$ VLPs, compared to the historical

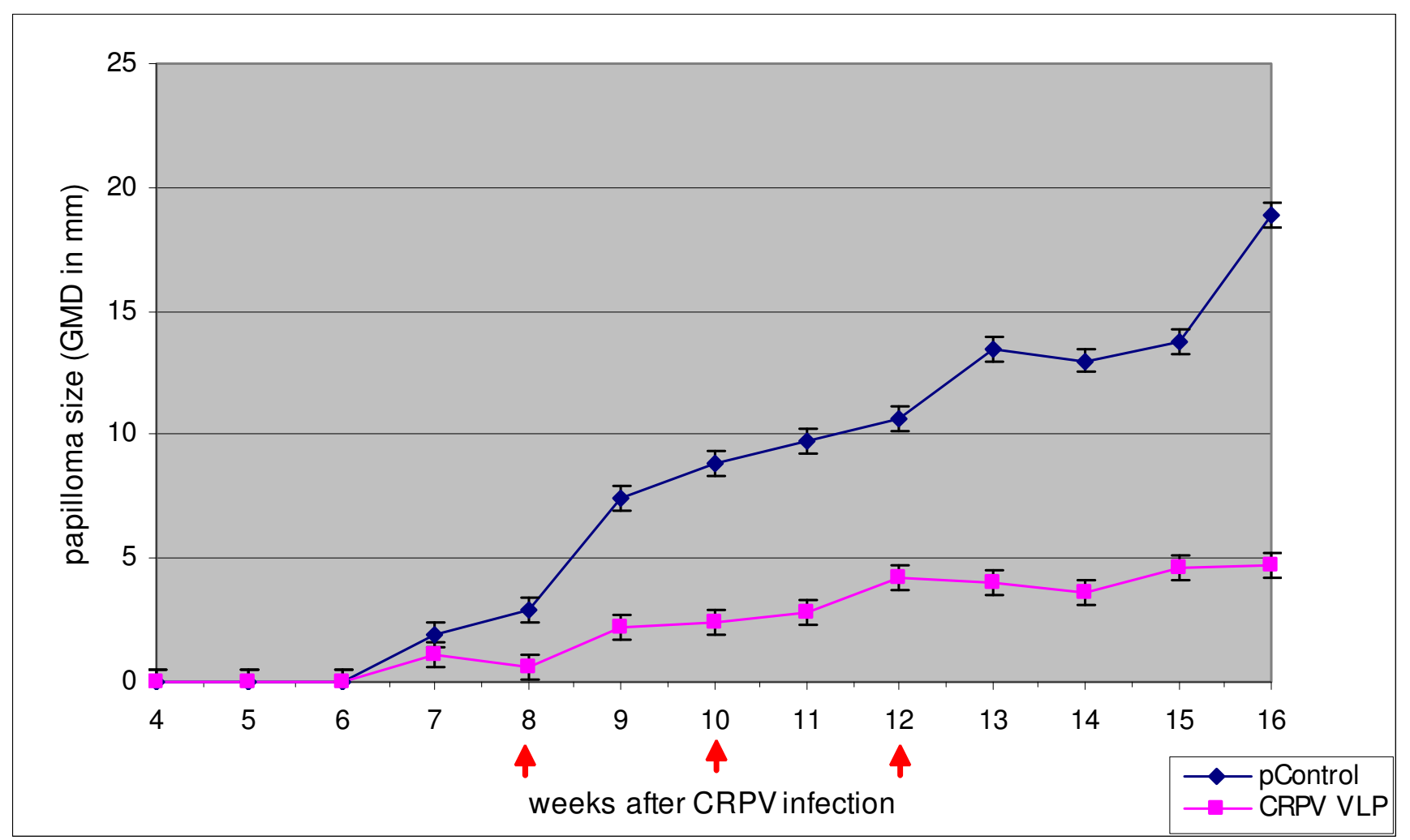

\section{Figure I}

Regression of papillomas on the backs of rabbits (NZW) following vaccination with CRPV VLPs. A total of nine rabbits were challenged with I0-fold dilutions of infectious CRPV (I0-fold dilution two sites per dilution). The rabbits were divided into two groups and immunized 3 times at 2 week intervals $(\uparrow)$ with CRPV VLPs $(n=5)$, or pControl $(n=4)$ antigen. The appearance of papillomas was monitored, the papilloma sizes were measured weekly beginning at week seven and the GMDs calculated. The mean GMDs and SEM of papillomas were plotted against time for the sites challenged with I0-2 dilution of infectious CRPV. ${ }^{*} P \leq 0.05$ (Mann-Whitney $U$-test). 
Table I: Rate of papilloma regression in each experimental rabbit group

\begin{tabular}{lllll}
\hline Vaccine & Number rabbits/group & \multicolumn{2}{c}{ Papilloma frequency } \\
\cline { 3 - 5 } & & +Complete regression (\%) & *Rate $P \leq$ value & $\wedge$ GMD $<5 \mathrm{~mm}(\%)$ \\
\hline CRPVVLP & 5 & $11 / 20(55)$ & $\leq 0.05$ & $15 / 20(75)$ \\
PControl & 4 & $0 / 16(0)$ & - & $0 / 16(0)$
\end{tabular}

+Number of papilloma sites that have completely regressed/total number of sites.

* $p$ value; papilloma regression of each group versus control group ( $\mathrm{pControl),} \mathrm{Mann-Whitney} \mathrm{U-test.}$

$\wedge$ Number of papilloma sites that have regressed below $5 \mathrm{~mm}$, GMD/total number of sites

controls [24]. Furthermore, comparable results were observed in a placebo-controlled human clinical trial: where women with pre-existing transient HPV 16 infection were vaccinated with HPV 16 L1 VLPs, complete protection was achieved $91.2 \%$ (95\% CI, 80-97) [13]. It is suggested that the aforementioned results could be due to the secondary effects on the adjacent cells and tissues triggered by immune recognition of a primary target, also called a bystander effect [23]. Thus the levels of L1 would indeed be detected by the immune system but would be below the experimental (such as western blot or immunofluorescence) detection levels and would therefore be unrecognised $[25,26]$.

Interestingly, the findings presented in the current study are in agreement with those mentioned above and we believe that the therapeutic effect afforded by CRPV L1 VLP is true. In deed, the CRPV VLP vaccine results presented here and the published commercial oncogenic HPV VLP vaccines have generated disparate results. One possible explanation for the differences observed in the CRPV model and the human trials is the route of immunisation, which could induce different immune pathways rendering different degrees of papilloma regression. Furthermore, the incidence of virus induction is dose dependant [27] and would certainly afford different papilloma regression in a natural and experimental study. In addition, although spontaneous regression of CRPVinduced papillomas have been reported to occur in less than $10 \%$ of infected rabbits [27] this was not observed in our study. The data shows that rabbits with existing CRPVinduced papillomas induced significant $(P \leq 0.05)$ papilloma regression following vaccination with CRPV L1 VLPs compared to the control group which grew papillomas progressively. Thus, the results of this pilot study are surprisingly encouraging as it demonstrates for the first time in a controlled based robust animal model the therapeutic potential of the CRPV L1 VLP vaccines.

\section{Competing interests}

The author(s) declare that they have no competing interests.

\section{Authors' contributions}

VAG designed the study, carried out the study and drafted the manuscript. EPR provided the VLPs. A-LW participated in the coordination of the study. All authors read and approved the final manuscript.

\section{Acknowledgements}

We thank Dr N. D. Christensen for providing infectious CRPV (CRPV ${ }_{\text {Her- }}$ shey strain), and Marleze Rheeder for excellent animal handling. This work was supported by grants of the South African Department of Arts Culture, Science and Technology Innovation Funding to ALW.

\section{References}

I. zur Hausen $\mathrm{H}$ : Papillomaviruses and cancer: from basic studies to clinical application. Nat Rev Cancer 2002, 2:342-350.

2. de Villiers EM, Fauquet C, Broker TR, Bernard HU, zur Hausen $\mathrm{H}$ : Classification of papillomaviruses. Virology 2004, 324:17-27.

3. Munoz N, Bosch FX, de Sanjose S: International Agency for Research on Cancer Multicenter Cervical Cancer Study Group Epidemiologic classification of human papillomavirus types associated with cervical cancer. N Engl J Med 2003, 348:5। 8-527.

4. Ferlay J, Bray F, Pisani P: Cancer Incidence, Mortality and Prevalence Worlwide. In IARC CancerBase No. 5 version 2.0 Lyon: IARCCPress; 2004.

5. Breitburd F, Kirnbauer R, Hubbert NL, Nonnenmacher B, Trin-DinhDesmarquet C, Orth G, Schiller JT, Lowy DR: Immunization with viruslike particles form cottontail rabbit papillomavirus (CRPV) can protect against experimental CRPV infection. J Virol 1995, 69:3959-3963.

6. Han R, Reed CA, Cladel NM, Christensen ND: Intramuscular injection of plasmid DNA encoding cottontail rabbit papillomavirus E1, E2, E6 and E7 induces T cell-mediated but not humoral immune responses in rabbits. Vaccine 1999, 17:1558-1566.

7. Frazer I: Prevention of cervical cancer through papillomavirus vaccination. Nature Reviews Immunol 2004, 4(I):46-54.

8. Jansen KU, Rosolowsky M, Schultz LD, Markus HZ, Cook JC, Donnelly J], Martinez D, Ellis RW, Shaw AR: Vaccination with yeastexpressed cottontail rabbit papillomavirus (CRPV) virus-like particles protects rabbits from CRPV-induced papilloma formation. Vaccine 1995, 13:1509-15|4.

9. Govan VA, Christensen ND, Berkower C, Jacobs WR Jr, Williamson $A L$ : Immunisation with recombinant BCG expressing the cottontail rabbit papillomavirus (CRPV) LI gene provides protection from CRPV challenge. Vaccine 2006, 24:2087-2093.

10. Kohl T, Hitzeroth II, Stewart D, Varsani A, Govan VA, Christensen ND, Williamson AL, Rybicki EP: Plant-produced cottontail rabbit papillomavirus $\mathrm{LI}$ protein protects against tumor challenge: a proof-of-concept study. Clin Vaccine Immunol 2006, 13:845-853.

II. Hines JF, Ghim SJ, Christensen ND: The expression of LI proteins of HPV-I, HPV-6, and HPV-I I display type-specific epitopes with native conformation and reactivity with neutralizing and non-neutralizing antibodies. Pathobiology 1994, 62:165-171.

12. Christensen ND, Höpfl R, DiAngelo SL, Cladel NM, Patrick SD Welsh PA, Budgeon LR, Reed CA, Kreider JW: Assembled baculo- 
virus-expressed human papillomavirus type II LI capsid protein virus-like particles are recognized by neutralizing monoclonal antibodies and induce high titres of neutralizing antibodies. I Gen Virol 1994, 75:227I-2276.

13. Koutsky LA, Ault KA, Wheeler CM, Brown DR, Barr E, Alvarez FB, Chiacchierini LM, Jansen KU, Proof of Principle Study Investigators: A controlled trial of a human papillomavirus type 16 vaccine. $\mathrm{N}$ Engl J Med 2002, 347:1645-165I.

14. Villa LL, Costa RL, Petta CA, Andrade RP, Ault KA, Giuliano AR, Wheeler CM, Koutsky LA, Malm C, Lehtinen M, Skjeldestad FE, Olsson SE, Steinwall M, Brown DR, Kurman RJ, Ronnett BM, Stoler MH, Ferenczy A, Harper DM, Tamms GM, Yu J, Lupinacci L, Railkar R, Taddeo FJ, Jansen KU, Esser MT, Sings HL, Saah AJ, Barr E: Prophylactic quadrivalent human papillomavirus (types $6,11,16$, and 18 ) LI virus-like particle vaccine in young women: a randomised double-blind placebo-controlled multicentre phase II efficacy trial. Lancet Oncol 2005, 6:27I-278.

15. Villa LL, Costa RL, Petta CA, Andrade RP, Paavonen J, Iversen OE Olsson SE, Hoye J, Steinwall M, Riis-Johannessen G, Andersson-Ellstrom A, Elfgren K, Krogh G, Lehtinen M, Malm C, Tamms GM, Giacoletti K, Lupinacci L, Railkar R, Taddeo FJ, Bryan J, Esser MT, Sings HL, Saah AJ, Barr E: High sustained efficacy of a prophylactic quadrivalent human papillomavirus types $6 / 11 / 16 / 18 \mathrm{LI}$ virus-like particle vaccine through 5 years of follow-up. $\mathrm{Br} J$ Cancer 2006, 95: I 459-I 466

16. Hildesheim A, Herrero R, Wacholder S, Rodriguez AC, Solomon D, Bratti MC, Schiller JT, Gonzalez P, Dubin G, Porras C, Jimenez SE, Lowy DR: Costa Rican HPV Vaccine Trial Group, Effect of human papillomavirus $16 / 18 \mathrm{LI}$ viruslike particle vaccine among young women with pre-existing infection: a randomized trial. JAMA 2007, 298:743-753.

17. Ruiz W, McClements WL, Jansen KU, Esser MT: Kinetics and isotype profile of antibody responses in rhesus macaques induced following vaccination with HPV 6, II, 16 and $18 \mathrm{LI}$ virus-like particles formulated with or without Merck aluminum adjuvant. J Immune Based Ther Vaccines 2005, 3:2.

18. Govan VA, Williamson AL: Rabbits immunised with recombinant BCG expressing the cottontail rabbit papillomavirus (CRPV) L2E7E2 genes induces regression of established papillomas. Virus Res 2007, I 27:43-48.

19. Marais D, Passmore JA, Maclean J, Rose R, Williamson AL: A recombinant human papillomavirus (HPV) type 16 LI-vaccinia virus murine challenge model demonstrates cell-mediated immunity against HPV virus-like particles. J Gen Virol 1999, 80:247I-245.

20. Williams OM, Hart KW, Wang EC, Gelder CM: Analysis of CD4(+) T-cell responses to human papillomavirus (HPV) type II LI in healthy adults reveals a high degree of responsiveness and cross-reactivity with other HPV types. J Virol 2002, 76:7418-7429.

21. Galloway DA: Papillomavirus vaccines in clinical trials. Lancet Infect Dis 2003, 3:469-475.

22. Stanley M: Immune intervention in HPV infections: current progress and future developments. Expert Rev Vaccines 2003, 2:615-617.

23. Roden R, Wu TC: How will HPV vaccines affect cervical cancer? Nat Rev Cancer 2006, 6:753-763.

24. Zhang LF, Zhou J, Chen S, Cai LL, Bao QY, Zheng FY, Lu JQ, Padmanabha J, Hengst K, Malcolm K, Frazer IH: HPV6b virus like particles are potent immunogens without adjuvant in man. Vaccine 2000, I 8: 105I-1058.

25. De Buijn ML, Greenstone HL, Vermeulen H, Melief CJ, Lowy DR Schiller JT, Kast WM: LI-specific protection from tumor challenge elicited by HPV 16 virus-like particles. Virology 1998, 250:37I-376.

26. Yang R, Wheeler CM, Chen X, Uematsu S, Takeda K, Akira S, Pastrana DV, Viscidi RP, Roden RB: Papillomavirus capsid mutation to escape dendritic cell-dependent innate immunity in cervical cancer. J Virol 2005, 79:674|-6750.

27. Reuter JD, Vivas-Gonzalez BE, Gomez D, Wilson JH, Brandsma JL, Greenstone HL, Rose JK, Roberts A: Intranasal vaccination with a recombinant vesicular stomatitis virus expressing cottontail rabbit papillomavirus $L I$ protein provides complete protection against papillomavirus-induced disease. J Virol 2002, 17:8900-8909.

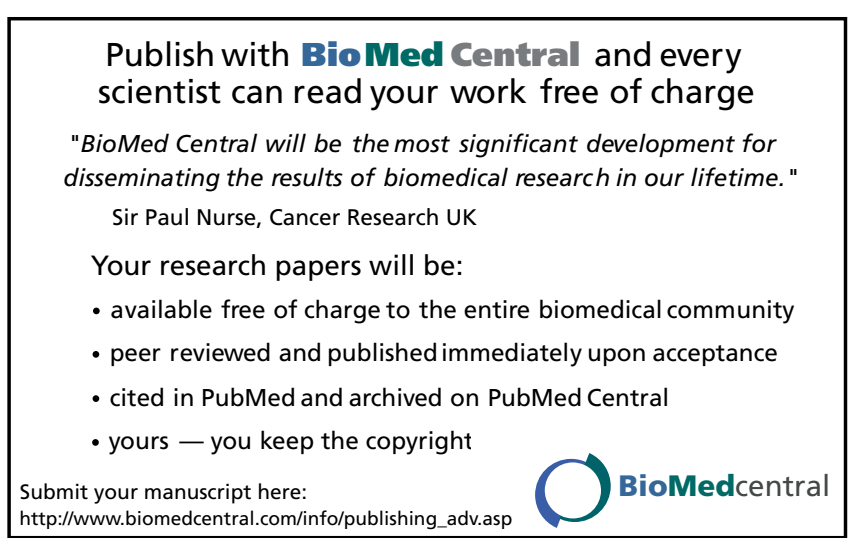

